\title{
Modeling of the horizontal and vertical anomalies in a reinforced concrete slab and their detection by using infrared thermography method
}

\author{
Abdelhamid Noufid* and Sougrati Belattar** \\ *Department of Civil Engineering, National School of Applied Sciences (ENSA), Agadir, Morocco \\ **Department of Physics, Faculty of Science Semlalia, Mly Abdellah Street, Marrakech, Morocco \\ *Corresponding Author: abdelhamid.noufid@ced.uca.ac.ma
}

Submitted: $10 / 06 / 2019$

Revised: $14 / 04 / 2020$

Accepted: 25/10/2020

\begin{abstract}
This article deals with the application of infrared thermography in the detection of anomalies in a reinforced concrete slab. This defect takes several forms, namely, horizontal, vertical, oblique, or spherical. In a previous article, in this journal (Vol 8, Issue 2), the case of inclined and spherical defect was investigated, while, in this one, it has studied the defect in horizontal and vertical positions, while varying, on one hand, the properties of the slab and, on the other hand, the characteristics of the defect. With finite element simulation software (COMSOL Multi-Physics), different simulations have been carried out to derive results on infrared thermography in reinforced concrete slabs. Following this study, the horizontal anomalies are easily detectable compared to the vertical ones, and the nature of the defect (air, water, and ice) influences the detection and that of the depth and width of the anomaly decides on the question of detectability, under the assumption that the infrared camera used in the detection is quite sensitive to the temperature contrast due to the presence of the anomaly.
\end{abstract}

Keywords: Reinforced concrete; Thermal image; Simulation; Defect; Detection.

\section{INTRODUCTION}

Nondestructive testing (NDT) can be applied to both old and new structures. For new structures, the principal applications are likely to be for quality control or the resolution of doubts about the quality of materials or construction. The testing of existing structures is usually related to an assessment of structural integrity or adequacy (IAEA, 2002). There are many NDT techniques, each based on different theoretical principles and each producing a different set of results regarding the physical properties of the structure (Sivakumar et al., 2019). Among these techniques, we focus on the method of infrared thermography (IRT). IRT has met an extensive popularity among the nondestructive technologies for building diagnostics (Kaylili et al., 2014; Cotic et al., 2015); it has become very popular due to its noncontact, quick and accurate nature, which enables its applicability to a broad range of cases. This method is used for the localization of delamination and other irregularities in the near surface region (Balayssac et al., 2012), the detection of plaster delamination (Meola et al., 2006), investigation of the masonry structure behind plaster (Arndt, 2010), the detection of moisture in the near surface region (Poblete et al., 2007), and many more. Indeed, the presence of an anomaly creates an observable thermal disturbance on the corresponding thermal image, such as water infiltration and moisture (Bomberg et al., 1988; Ljungberg, 1994). The method of IRT is based on infrared radiation (below red), a form of electromagnetic radiation with longer wave lengths than those of visible light (Usamentiaga et al., 2014), and 
the material used to capture these radiations is the infrared camera. IR cameras are used to detect infrared radiation, which is emitted from the surface of an object and converts this into a readable thermal image (Hart, 1990). Active IRT is mostly used in nondestructive testing applications, where an external stimulus is applied to the specimen in order to induce relevant thermal contrasts between regions of interest (Ibarra et al., 2003; Fox et al., 2014). The analysis by professional thermal images allows detecting the existence of anomalies in the concrete structure (Janku et al., 2017), and thus taking necessary measures to avoid possible catastrophes. Noufid et al. (2019) have simulated that inclined and spherical defects can be detected in reinforced concrete slabs, under certain conditions, by the NDT method. We will complete this last study by foreseeing other cases of defects, namely, horizontal and vertical defects. Moreover, the simulations were carried out by commercial software, namely, COMSOL Multi-Physics. It should be noted that the simulations have shown their effectiveness in terms of crack detection (Jianda et al., 2020).

\section{DESCRIPTION OF THE GENERAL PROBLEM}

The cracks generated inside the slabs due to several physical or chemical factors are filled with water during rainy periods. The water contained in the so-called cracks at the level of a reinforced concrete slab freezes in cold seasons, which gives rise to an increase in volume and consequently to a pushing force that tends to propagate the crack (Fig. 1). The ice plays the role of glue that makes the concrete on both sides of the crack remain attached until the arrival of hot seasons, and at that moment, the problem begins to be observed; in other words, these are detachment parts of concrete and appearance of steel reinforcements.



Fig. 1. Concrete blocks stand out from a slab.

The exposure of steel reinforcement to the air generates the phenomenon of rust and consequently the decrease in the diameter of the steel bars. Fig. 2 summarizes what we have just described. At first, the slab is in a healthy state (Fig. 2-1); over time and due to external factors, there is an appearance of cracks (Fig. 2-2); these cracks can be filled with air or water (Fig. 2-3), in which, in cold weather, this water expands and pushes the layer of concrete; therefore, a burst of concrete occurs (Fig. 2-4). This research aims to detect cracks inside the slab by a nondestructive method. There are the means of Nondestructive Control (NDT), so it will focus on the infrared method to highlight the internal defects and subsequently anticipate the detachment of concrete by preventive methods.

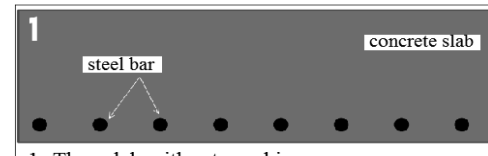

1- The salab without cracking

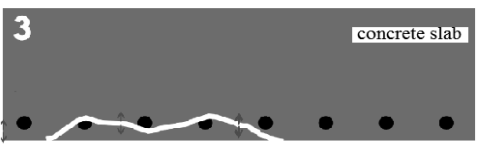

3- Crack expansion



2- Appearance of cracking

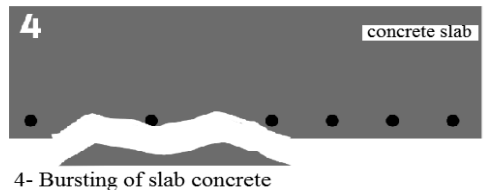

Fig. 2. The four steps of detaching the concrete parts in the slab. 


\section{PRESENTATION OF THE EXPERIMENTAL RESULTS}

Fig. 3 represents the modeling of the slab to be studied; it is a slab of square shape of $1 \mathrm{~m}$ of side and thickness of $20 \mathrm{~cm}$, built in reinforced concrete.

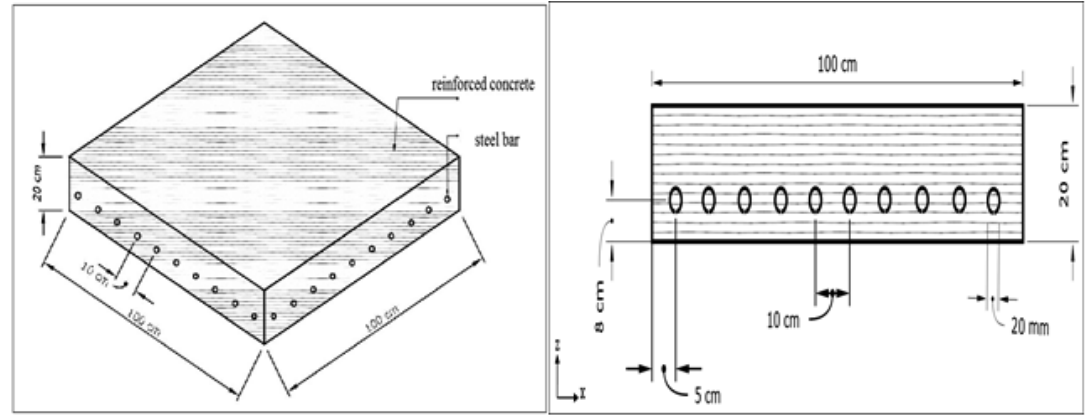

Fig. 3. Geometry of the slab (left) and cross-section (right).

This slab contains two rows of reinforcement located at a depth of $\mathrm{p}=8 \mathrm{~cm}$ from the lower surface of the slab. The steel bars are spaced at a distance of $\mathrm{d}=10 \mathrm{~cm}$ from center to center.

\section{FINITE EMELMENT METHODE SIMULATIONS}

In order to illustrate the considerations mentioned above, we present the results of calculations of the thermal response of the reinforced concrete slab located at the thermal conditions in Figure 4.

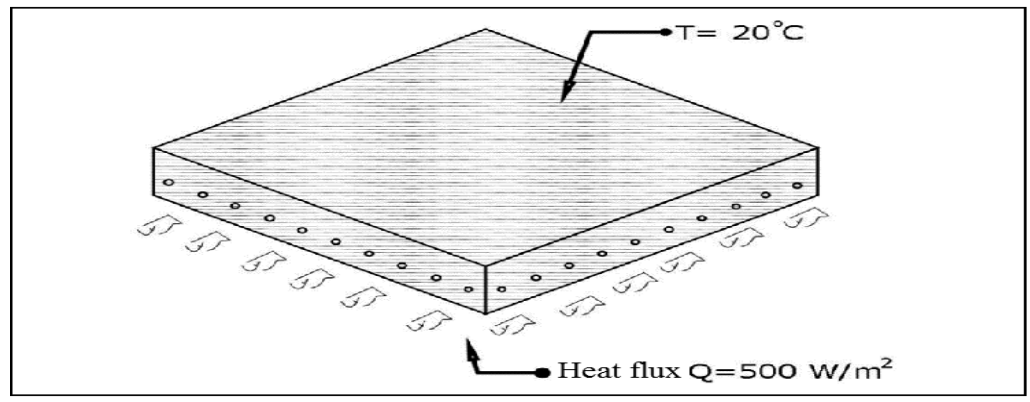

Fig. 4. Boundary conditions of the slab.

The bottom surface of the structure is uniformly heated with a permanent heat source, the power of the heat flux transmitted by this source is $500 \mathrm{~W} / \mathrm{m}^{2}$, the upper face being maintained at a constant temperature $\mathrm{T}=20^{\circ} \mathrm{C}$ (using the initial conditions on the software), and the other faces are supposed to be isolated (heat flux is $\mathrm{Q}=0 \mathrm{~W} / \mathrm{m}^{2}$ ). The initial temperatures considered for the lower surface and for the ambient environment were $20^{\circ} \mathrm{C}$. The materials used in this study are characterized by the thermophysical properties in Table 1:

Table 1. Thermophysical properties of materials used.

\begin{tabular}{cccc}
\hline Material & $\begin{array}{c}\text { Thermal Conductivity } \\
(\mathbf{W} / \mathbf{m . K})\end{array}$ & $\begin{array}{c}\text { Density } \\
\left(\mathbf{K g} / \mathbf{m}^{\mathbf{3}}\right)\end{array}$ & $\begin{array}{c}\text { Heat capacity } \\
(\mathbf{J} / \mathbf{K g} . \mathbf{K})\end{array}$ \\
\hline Concrete & 1.8 & 2300 & 880 \\
\hline Structure steel & 44.5 & 7850 & 475 \\
\hline Glace & 1.05 & 918 & 2052 \\
\hline
\end{tabular}




\section{Horizontal cracks}

The horizontal cracks in the slabs are related to a deformation or movement of a part of the building. This movement can be caused by

- Differential settlement (Laure, 2006), linked to a clay soil. The clays swell in durably rainy weather and shrink during acute or prolonged drought episodes.

- An accidental event, such as pipe breakage.

The building materials evolve with the seasons; the weather conditions themselves degrade the foundations and slabs. Some cracks can be dangerous; that is why it is important to know how to recognize them. The aim of this part is to study the detectability of different configurations of horizontal cracks in a reinforced concrete slab (Nguyen et al., 2005).

\section{Effect of crack depth}

The model used in this study is identical to that of Fig. 3, in which it introduced a horizontal crack, length $\mathrm{L}=30$ $\mathrm{cm}$ and width $1=20 \mathrm{~cm}$ (Fig. 5).
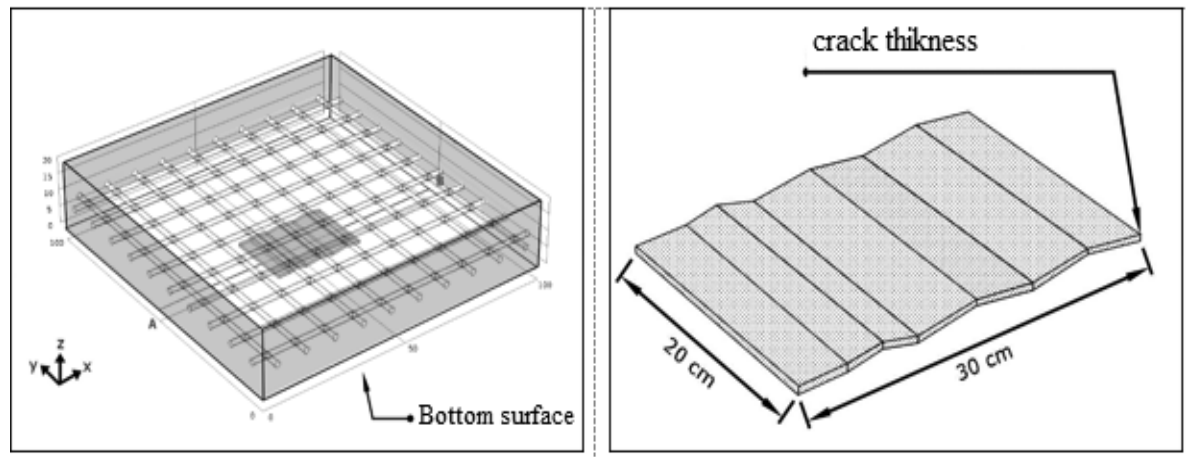

Fig. 5. Geometry of the horizontal crack.

The thermographic images given below represent the simulation results of the lower surface of the slab (Fig. 7), and the curves (Fig. 8) represent the temperature difference along the central axis of the lower face. In order to study the influence of the position in the detection of ice cracks in a reinforced concrete slab, we consider an ice crack of thickness e $=8 \mathrm{~mm}$, placed in the slab at different depths "p" (Fig. 6), with $\mathrm{p}=[1 \mathrm{~cm}, 4 \mathrm{~cm}, 9 \mathrm{~cm}$, and $12 \mathrm{~cm}]$.

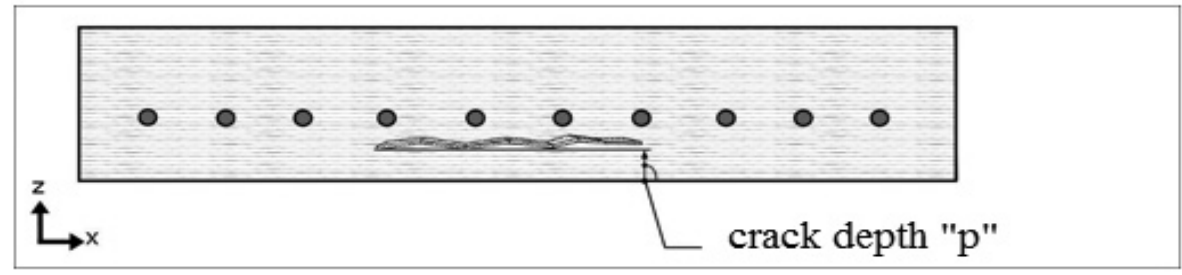

Fig. 6. View of the cross-section of the cracked slab.

The thermograms in Fig. 7 represent the distribution of the temperature of the lower surface, and Fig. 8 represents the evolution of the temperature profile along the line $\mathrm{AB}$ for depth values (p): 1, 4, 9, and $12 \mathrm{~cm}$. 


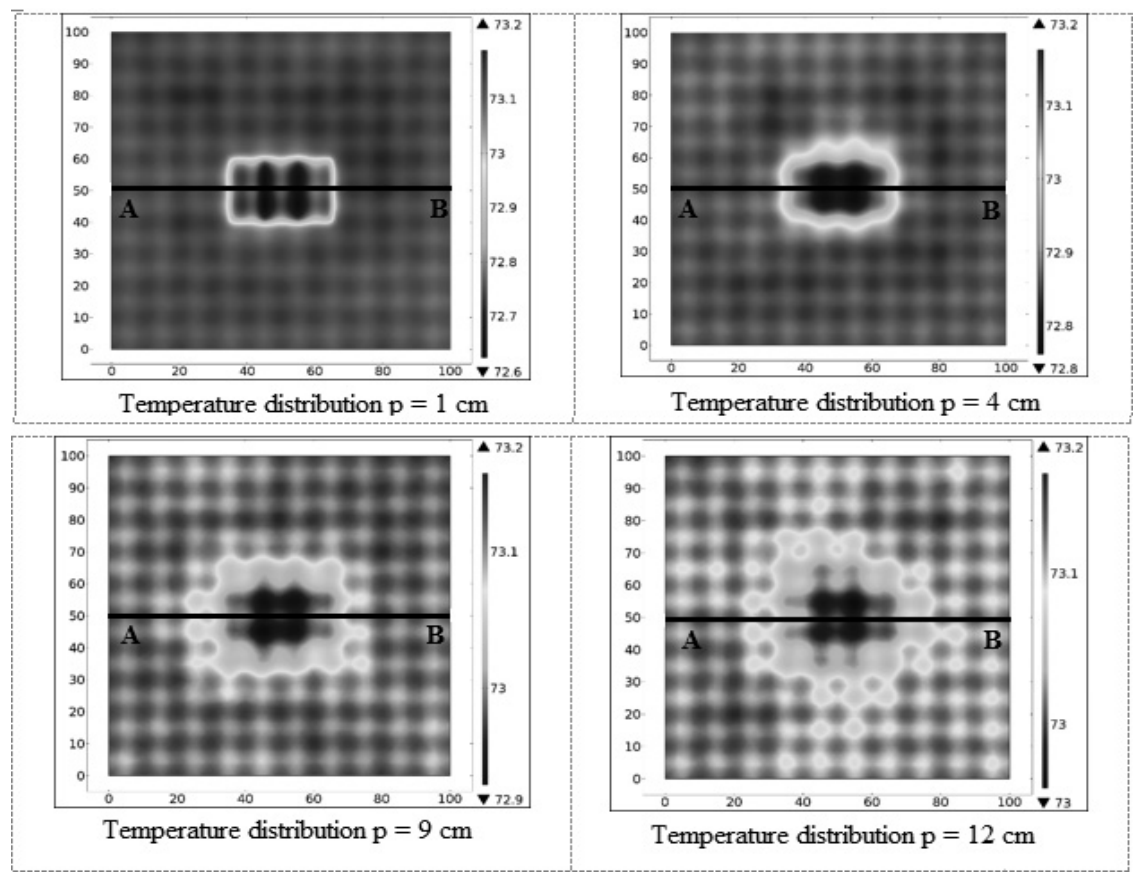

Fig. 7. Thermal images at different depths.

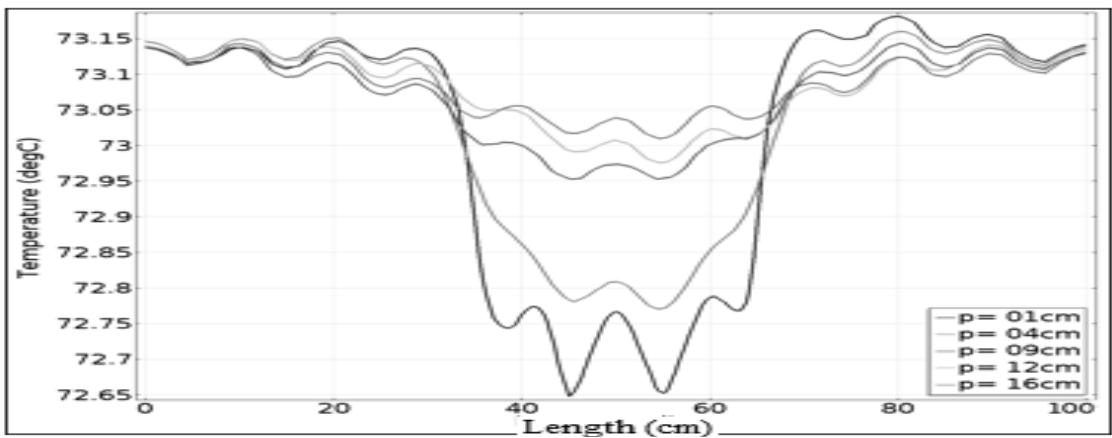

Fig. 8. Temperature profiles along the $\mathrm{AB}$ axis.

The results obtained are represented in the form of thermal images (thermograms). From Fig. 7 it can be seen that the decrease in temperature indicated by the appearance of cold blue spots reflects the presence of a defect in the form of an ice crack. The contrast observed at the surface depends on the depth of the crack (for the same thickness). The effect of the position of the crack on the detection of the latter is remarkable. It can be noted that the closer the crack to the surface, the greater the intensity of the thermal task, and its detection becomes easier.

Table 2. Maximum and minimum temperature values.

\begin{tabular}{ccccc}
\hline Depth of crack $[\mathbf{c m}]$ & $\mathbf{1}$ & $\mathbf{4}$ & $\mathbf{9}$ & $\mathbf{1 2}$ \\
\hline Maximum temperature $\left[{ }^{\circ} \mathrm{C}\right]$ & 73.18 & 73.159 & 73.142 & 73.149 \\
\hline Minimum temperature $\left[{ }^{\circ} \mathrm{C}\right]$ & 72.648 & 72.771 & 72.953 & 72.977 \\
\hline$\Delta \mathrm{T}\left[{ }^{\circ} \mathrm{C}\right]$ & 0.532 & 0.388 & 0.189 & 0.172 \\
\hline
\end{tabular}


Table 2 illustrates the temperature differences along the $\mathrm{AB}$ axis for different depths $\mathrm{p}$. We can see that the crack detection gradually becomes less and less accurate as the crack moves away from the surface. In general, according to Fig. 9, the detectability of ice cracks with a depth of less than $9 \mathrm{~mm}$ is possible, while the detection of those at a greater depth requires highly sensitive infrared cameras.

\section{Effect of crack thickness}

In this part, we consider a reinforced concrete slab containing three ice cracks (Fig. 9) of different thicknesses, $\mathrm{e} 1=1 \mathrm{~mm}, \mathrm{e} 2=4 \mathrm{~mm}$, and e $3=8 \mathrm{~mm}$, located in the middle of the slab at a depth $\mathrm{p}=5 \mathrm{~cm}$ from the bottom surface.
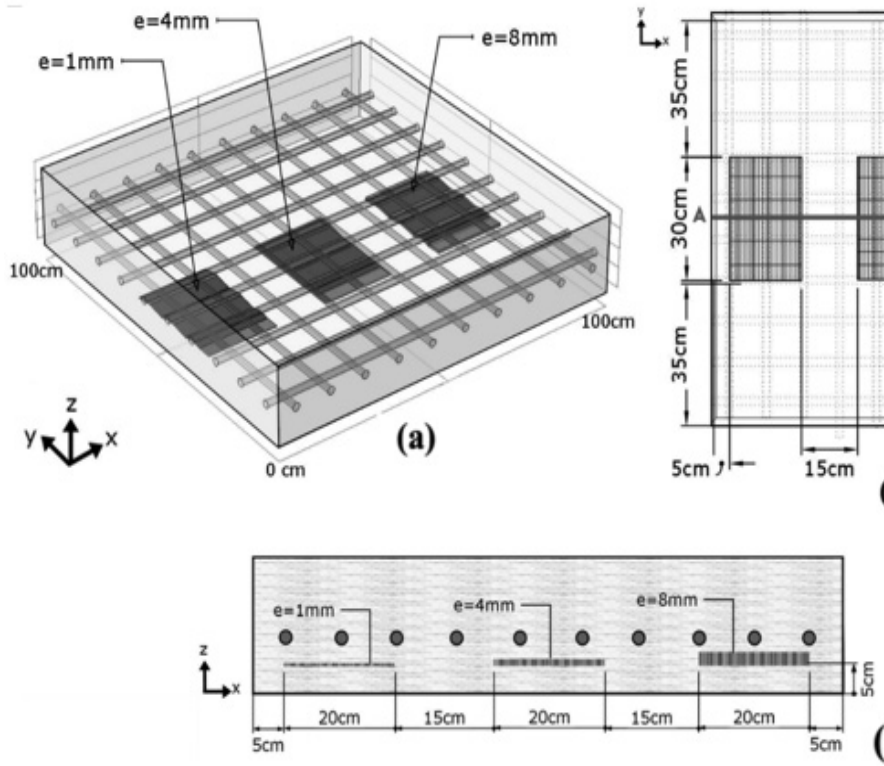



(b)

Fig. 9. (a) 3D geometry; (b) upper side; (c) cross-section slab.

Fig. 10 shows the distribution of the temperature along the lower surface, and we observe three tasks of different intensities, with the most intense task being that of thickness e $3=8 \mathrm{~mm}$.
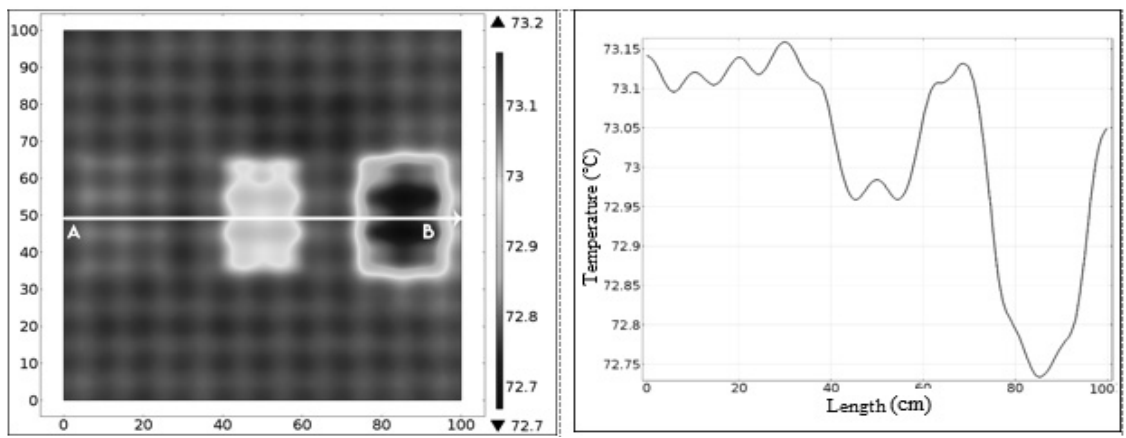

Fig. 10. Simulation results for different thicknesses.

It can be noted that the thickness cracks of e $2=4 \mathrm{~mm}$ and e $3=8 \mathrm{~mm}$ appear without any difficulty on the thermographic image; however, the thickness crack e1 $=1 \mathrm{~mm}$ becomes more difficult. The corresponding curve shows that the temperature difference in the zone of existence of the crack of thickness e $1=1 \mathrm{~mm}$ can reach a value $\Delta \mathrm{T}$ 
$=0.05{ }^{\circ} \mathrm{C}$, and knowing that most infrared cameras have a sensitivity between $0.15^{\circ} \mathrm{C}$ and $0.045^{\circ} \mathrm{C}$, the detection of this type of crack is almost impossible.

\section{Diameter effect of steel bars}

Let us look at the influence of the diameter of the steel bars on the detection of the ice crack. To do this, we place a longitudinal crack of thickness $\mathrm{e}=8 \mathrm{~mm}$ in a reinforced concrete slab at a depth $\mathrm{p}=9 \mathrm{~cm}$ from the bottom surface, and the steel bars are, respectively, $\mathrm{d}=10 \mathrm{~mm}, 20 \mathrm{~mm}$, and $32 \mathrm{~mm}$ (Fig. 11).

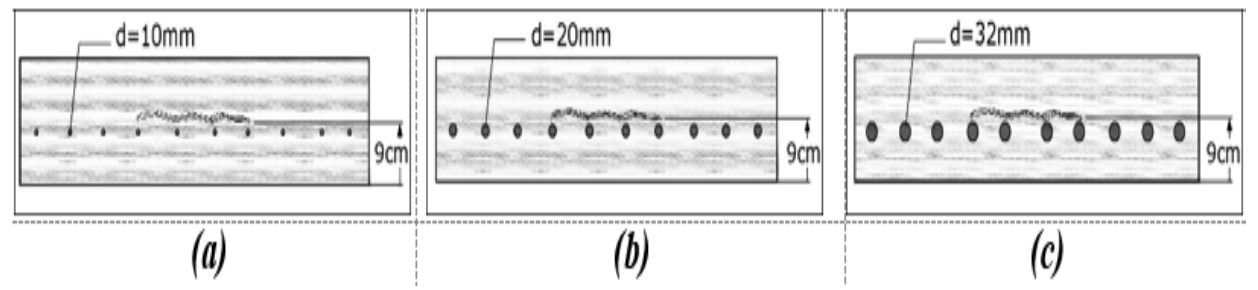

Fig. 11. (a) $d=10 \mathrm{~mm}$; (b) $=20 \mathrm{~mm}$; (c) $=32 \mathrm{~mm}$.

Fig. 12 shows the simulated thermographic image at the bottom surface of the slab, and Fig. 13 shows the temperature difference along the line $\mathrm{AB}$. The effect of diameter of the steel bars is remarkable on the thermographic image. In Fig. 12, there is a significant change in the temperature distribution on the three surfaces of the concrete slab. The maximum temperature in the lower surface slab having a reinforcement network of diameter $\mathrm{d}=10 \mathrm{~mm}$ is larger than the other two, and this is due to the increase of the thermal resistance, which prevents the diffusion of the heat in the slab. One thing is explained by the following equation (Noufid et al. 2019).

$$
\phi=\mathrm{e} / \lambda
$$

where $\phi$ : thermal resistance $\left(K \cdot m^{2} \cdot W^{-1}\right)$

e: thickness of steel bars $(m)$

$\lambda$ : thermal conductivity $(W / m . K)$.

The thermal tasks of ice cracks become less intense as the diameter increases.



Fig. 12. Thermal images for different diameters.

Fig. 13 gives the temperature difference along the $\mathrm{AB}$ axis for the three diameters of the bars, and it is remarkable that $\Delta \mathrm{T}$ minimum is equal to $0.146^{\circ} \mathrm{C}$, which makes its detection easier. 


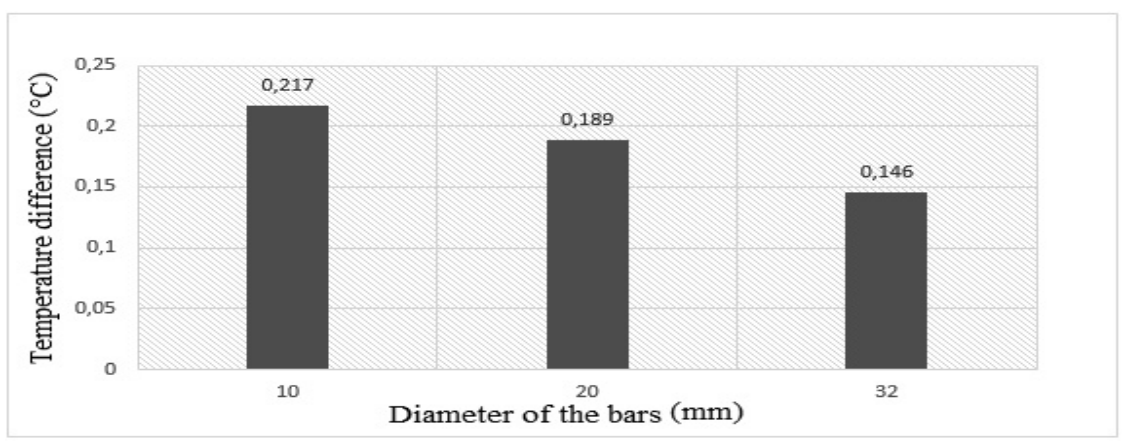

Fig. 13. Temperature variation $\Delta \mathrm{T}$ according to the diameter.

\section{Effect of thermophysical parameters}

In order to illustrate the influence of the thermophysical parameters on the detection of the ice crack, we considered the structure of the slab (Fig. 14.a), which contains three defects, located at a depth $\mathrm{p}=2 \mathrm{~cm}$ (Fig. 14.b).

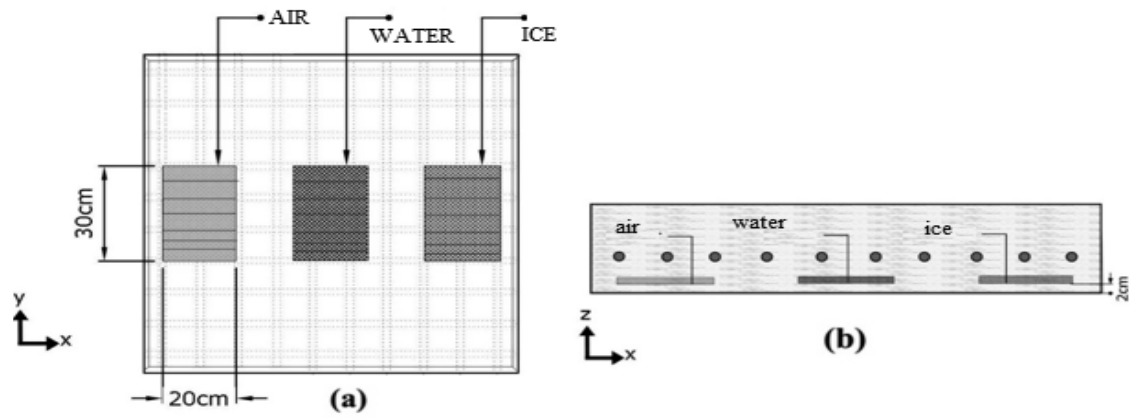

Fig. 14. (a) Upper side; (b) cross-section slab.

The first crack is filled with air, the second with water, and the third with ice. The thermophysical properties of these materials are given in Table 3 .

Table 3. Thermophysical properties of materials used (Noufid et al., 2019).

\begin{tabular}{cccc}
\hline Material & $\begin{array}{c}\text { Thermal conductivity } \\
(\mathbf{W} / \mathbf{m . K})\end{array}$ & $\begin{array}{c}\text { Density } \\
\left(\mathbf{K g} / \mathbf{m}^{\mathbf{3}}\right)\end{array}$ & $\begin{array}{c}\text { Heat capacity } \\
(\mathbf{J} / \mathbf{K g} . \mathbf{K})\end{array}$ \\
\hline Air & 0.02 & 1.057 & 1005 \\
\hline Water & 0.6 & 1000 & 1.293 \\
\hline Ice & 1.05 & 918 & 2052 \\
\hline
\end{tabular}

Fig. 15 (left) represents the simulated thermographic image of the lower surface of the slab with the existence of three different cracks, and Fig. 15 (right) represents the thermogram of the same surface without any cracking. These images illustrate the influence of thermophysical parameters for crack type knowledge in the slab. Indeed, when the defect is of air or water nature, the flow of heat passes through the concrete structure avoiding the anomaly, then a heat accumulation occurs in the defect zone, which generates, consequently, an increase in the temperature compared to the neighborhood. In the case of an ice crack, the heat flow is absorbed by the crack, which implies a drop in the temperature in this area compared to its vicinity. 


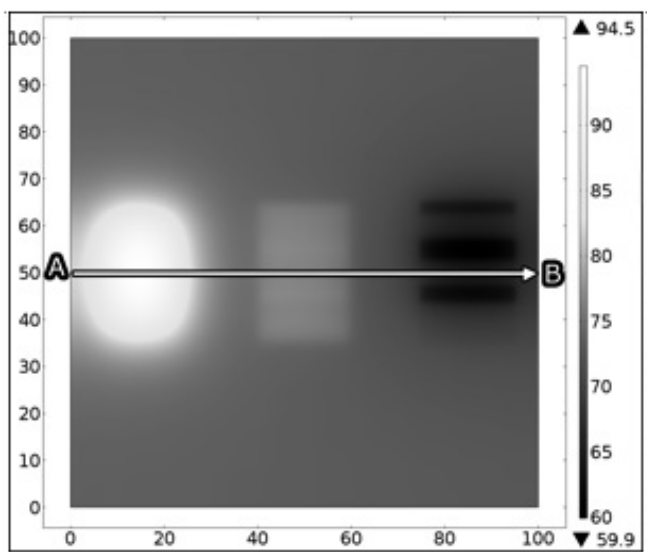

(a)



(b)

Fig. 15. Comparison between the slab with defects (a) and the slab without defects (b).

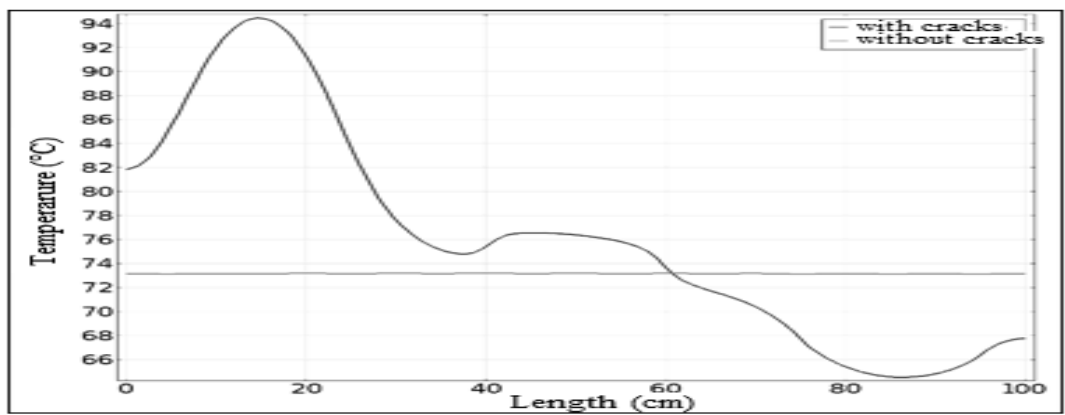

Fig. 16. Temperature evolution along the $\mathrm{AB}$ axis.

Air is an insulating element because of low thermal conductivity, but it has a high thermal diffusivity (of the order of a steel), which makes it easily detectable compared to water and ice (Fig. 16).

\section{Temporal study}

Among the factors influencing the detection of defects by infrared thermography in reinforced concrete slabs, there is the thickness of the crack and its position relative to the surface, as well as the heating time of the structure and the moment of taking thermal images. To study this parameter, we consider two ice cracks of thicknesses $4 \mathrm{~mm}$ and $8 \mathrm{~mm}$, respectively, placed in the positions $\mathrm{x}=25 \mathrm{~cm}, \mathrm{y}=50 \mathrm{~cm}$, and $\mathrm{x}=75 \mathrm{~cm}, \mathrm{y}=50 \mathrm{~cm}$. Both cracks are located at depths $\mathrm{p}=[1 \mathrm{~cm}, 4 \mathrm{~cm}$, and $8 \mathrm{~cm}]$ from the surface (Fig. 17).

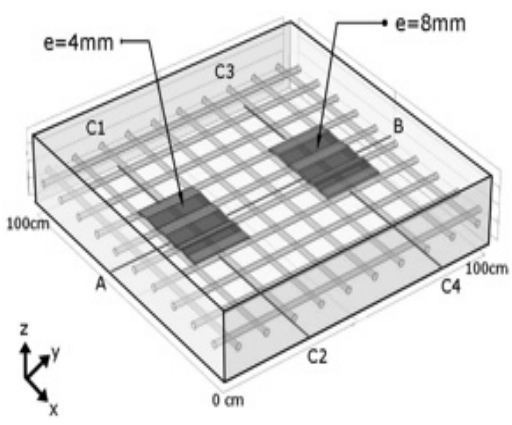

Fig. 17. Geometry of the structure studied in 3D. 
A constant heat flow $\left(\mathrm{Q}=500 \mathrm{~W} / \mathrm{m}^{2}\right)$ is applied to the lower surface of the slab for a certain determined period of time in order to cause a sufficiently large and measurable temperature difference $\Delta \mathrm{T}$ by the camera between the normal zones of the slab and defective areas. The experiment was repeated for the depths $1 \mathrm{~cm}, 4 \mathrm{~cm}$, and $9 \mathrm{~cm}$. Fig. 18 represents the recorded thermograms of the lower surface, and Fig. 19 represents the evolution of the profile of the temperature along the lines $\mathrm{C} 1 \mathrm{C} 2$ and $\mathrm{C} 3 \mathrm{C} 4$ after a heating period: $\mathrm{t} 1=2 \mathrm{~min}, \mathrm{t} 2=6 \mathrm{~min}$, and $\mathrm{t} 3=10 \mathrm{~min}$. It is relative to the $1 \mathrm{~cm}$ depth, because the others give images without contrasts.

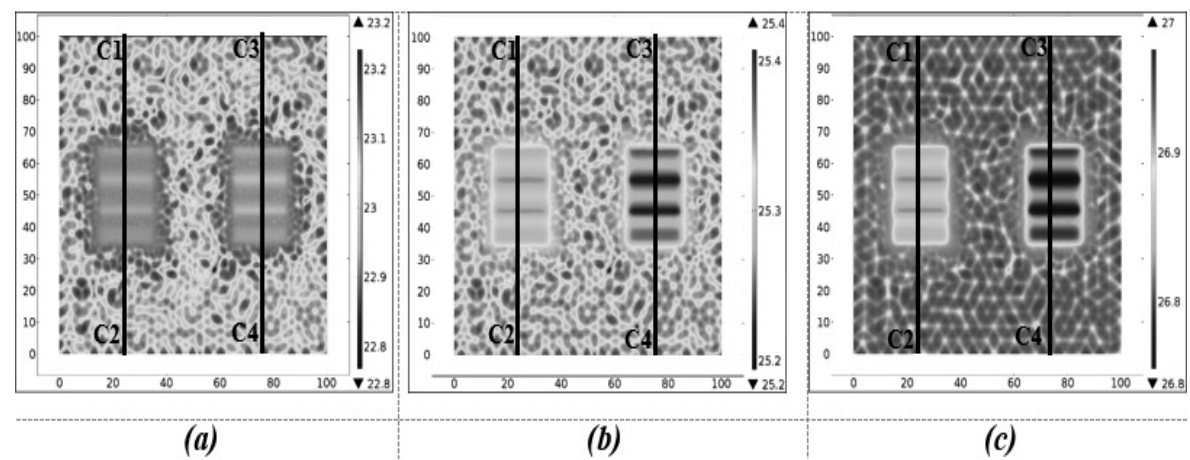

Fig. 18. Thermal images after (a) $\mathrm{t} 1=2 \mathrm{~min}$; (b) $\mathrm{t} 2=6 \mathrm{~min}$; (c) $\mathrm{t} 3=10 \mathrm{~min}$.

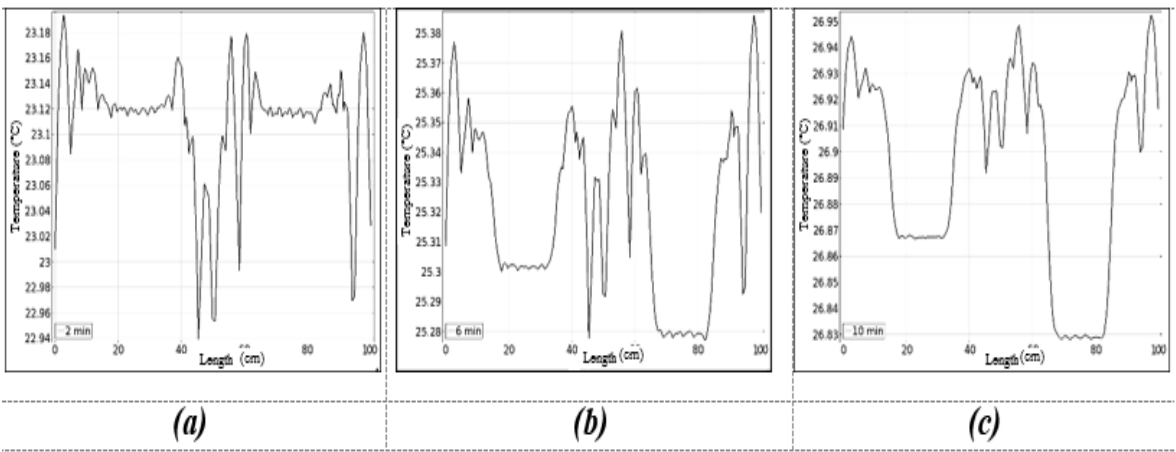

Fig. 19. Temperature profiles along the $A B$ : (a) $t 1=2 \min ;$ (b) $t 2=6$ min; (c) $t 3=10$ min.

The heating time of the slab is a very important factor in the detection of defects; the more the reinforced concrete slab is heated, the more the thermal task is clear. The area of the crack of thickness $4 \mathrm{~mm}$ appears less hot than the thickness of $8 \mathrm{~mm}$.



Fig. 20. Temperature evolution along lines $\mathrm{C} 1 \mathrm{C} 2$ and $\mathrm{C} 3 \mathrm{C} 4$. 
The temperature curves in Fig.20 show that the temperature differences $\Delta \mathrm{T}$ are strongly related to the thickness and position of the defect. A large thickness would result in a large value of $\Delta \mathrm{T}$ of the defect as shown in Fig. 20. The detection of the presence of the two defects $(4 \mathrm{~mm}$ and $8 \mathrm{~mm}$ ) would be simple after 5 min of heating by means of appropriate equipment of sensitivity lower than $0.035^{\circ} \mathrm{C}$. It is important to note that detection of both defects is possible by using a standard equipment with a sensitivity of less than $0.15^{\circ} \mathrm{C}$; it is only necessary to heat for a duration of more than $20 \mathrm{~min}$, which is still a reasonable period for detection. Fig. 21 shows the recorded thermograms of the lower surface, and Fig. 22 shows the evolution of the temperature profile along lines $\mathrm{C} 1 \mathrm{C} 2$ and $\mathrm{C} 3 \mathrm{C} 4$ after a heating period: $\mathrm{t} 1=10 \mathrm{~min}, \mathrm{t} 2=26 \mathrm{~min}$, and $\mathrm{t} 3=40 \mathrm{~min}$.

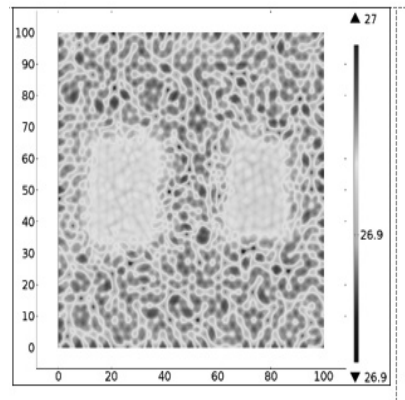

(a)

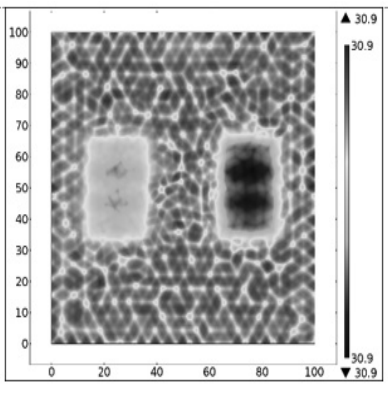

(b)

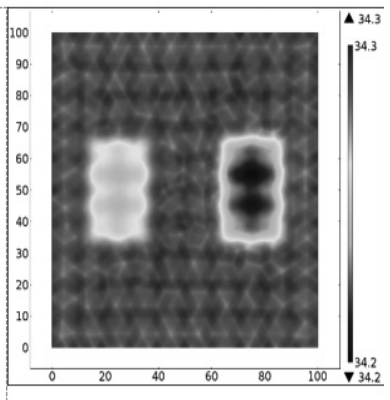

(c)

Fig. 21. Thermograms for durations (a) $\mathrm{t} 1=10 \mathrm{~min}$; (b) $\mathrm{t} 2=26 \mathrm{~min}$; (c) $\mathrm{t} 3=40 \mathrm{~min}$.

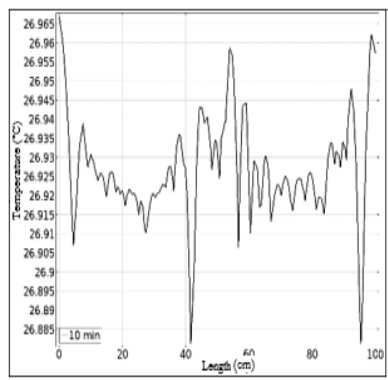

(a)



(b)



(c)

Fig. 22. Temperature profiles along AB: (a) $\mathrm{t} 1=10 \mathrm{~min}$; (b) $\mathrm{t} 2=26 \mathrm{~min}$; (c) $\mathrm{t} 3=40 \mathrm{~min}$.

The temperature curves (Fig. 23) show that temperature differences $\Delta \mathrm{T}$ increase with time. The first crack (4 mm) becomes detectable by an apparatus of sensitivity lower than $0.035{ }^{\circ} \mathrm{C}$ after $35 \mathrm{~min}$ of heating, against the second crack $(8 \mathrm{~mm})$, which becomes detectable by the same equipment after $28 \mathrm{~min}$. When using standard devices with a sensitivity of less than $0.15^{\circ} \mathrm{C}$, it is necessary to heat for a period exceeding one hour.

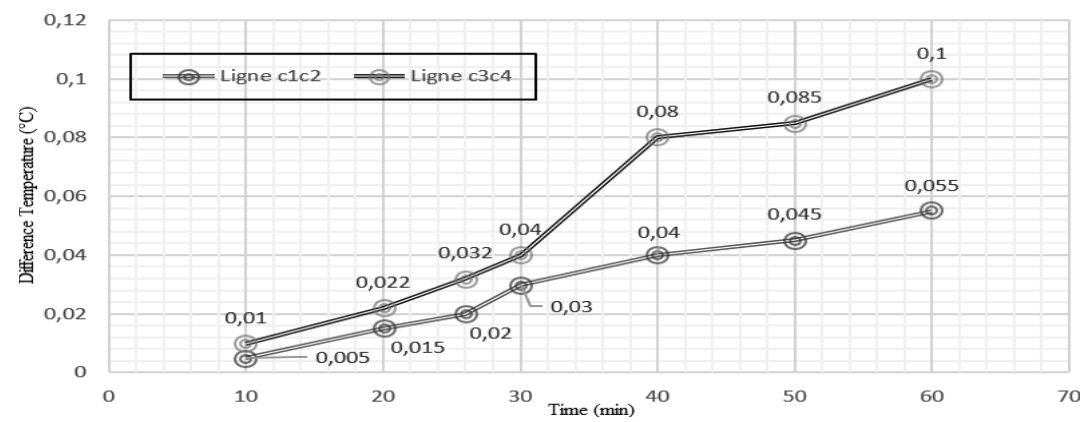

Fig. 23. Evolution of the temperature along lines $\mathrm{C} 1 \mathrm{C} 2$ and $\mathrm{C} 3 \mathrm{C} 4$. 
Fig. 24(a) represents the recorded thermograms of the lower surface, and Fig. 24(b) shows the evolution of the temperature profile along lines $\mathrm{C} 1 \mathrm{C} 2$ and $\mathrm{C} 3 \mathrm{C} 4$ after a heating period: $\mathrm{t} 1=1 \mathrm{~h}$ and $\mathrm{t} 2=4 \mathrm{~h}$.

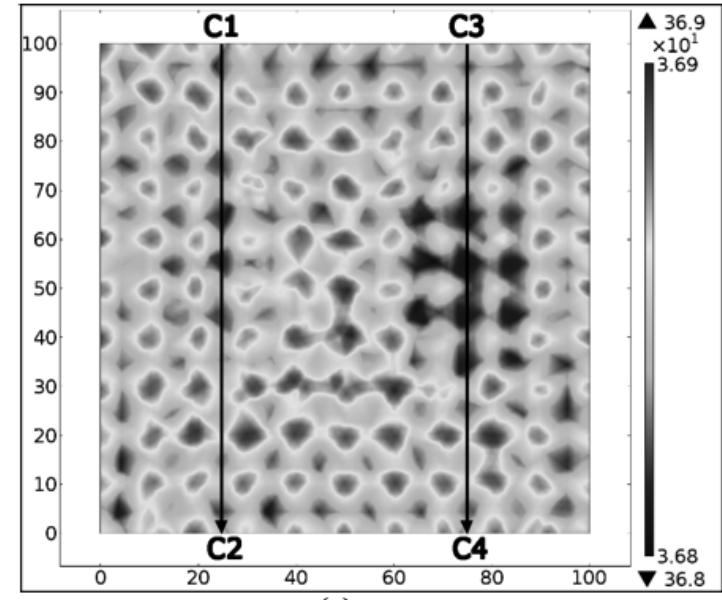

(a)



(b)

Fig. 24. Thermal images after $1 \mathrm{~h}(\mathrm{a})$ and $4 \mathrm{~h}(\mathrm{~b})$.

From Fig. 24 it can be seen that the thermal difference between reinforcement and concrete on one side and ice cracks on the other side on the lower surface becomes very small. To detect the temperature differences in a precise way, we realized a thermal profile along lines $\mathrm{C} 1 \mathrm{C} 2$ and $\mathrm{C} 3 \mathrm{C} 4$, and the results obtained are given in Fig. 25.

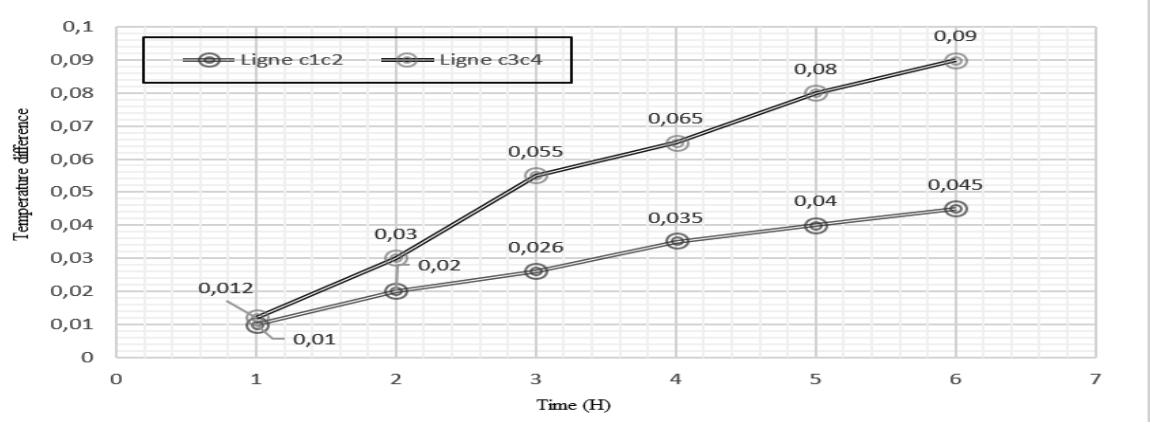

Fig. 25. Different temperature along axes $\mathrm{C} 1 \mathrm{C} 2$ and $\mathrm{C} 3 \mathrm{C} 4$.

In this time, cracks are located at a greater depth $(9 \mathrm{~cm})$, and the detectability of their presence becomes very difficult. Using sophisticated equipment with a sensitivity of less than $0.035{ }^{\circ} \mathrm{C}$, the first crack $(4 \mathrm{~mm})$ will not be detectable until after 4 hours of heating, and the second crack $(8 \mathrm{~mm})$ becomes detectable after 2 hours and 20 minutes. The majority of infrared cameras have a battery life that does not exceed $4 \mathrm{~h}$, which makes the detectability of cracks placed in depths exceeding $4 \mathrm{~cm}$ difficult to achieve.

\section{Vertical cracks}

In this part, we adopted the same structure of dimensions $100 \mathrm{~cm} \times 100 \mathrm{~cm} \times 20 \mathrm{~cm}$, in which it introduced a vertical crack, width $\mathrm{L}=4 \mathrm{~cm}$, height $\mathrm{h}=10 \mathrm{~cm}$, and the thickness is variable (Fig. 26). 


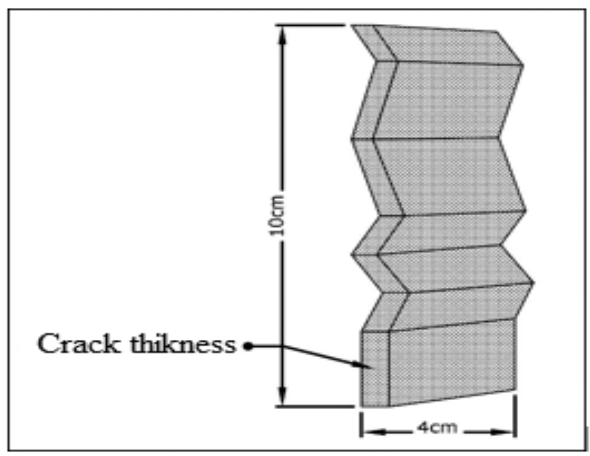

Fig. 26. Geometry of the vertical crack.

The thermographic images given below represent the results of the simulations of the lower surface of the slab, and the curves represent the temperature difference along the lines studied.

\subsubsection{Effect of geometric parameters}

In order to study the influence of geometric parameters (depth and thickness) on the detection of vertical ice cracks, we considered 12 ice cracks located in a reinforced concrete slab (Fig. 27).
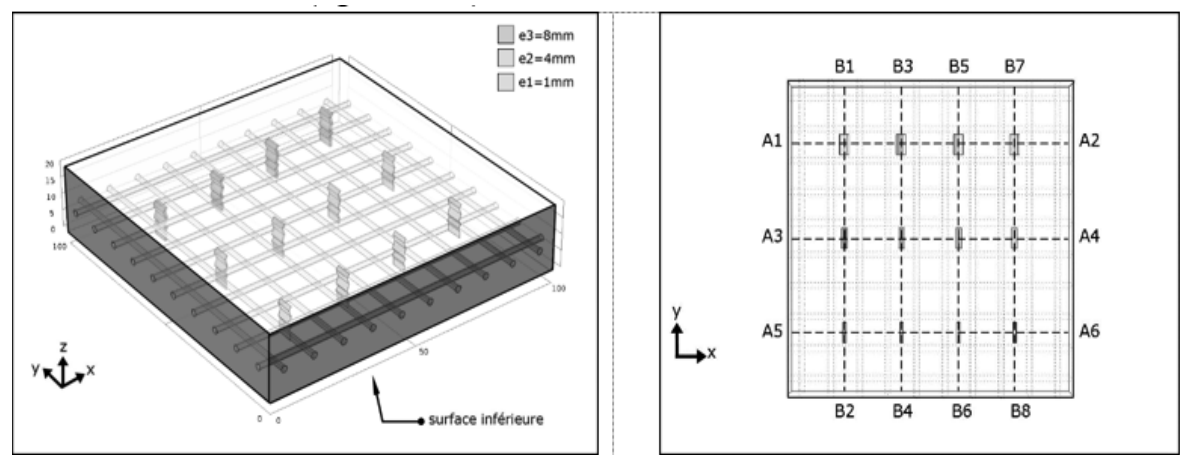

Fig. 27. Geometry of the vertical crack.

The cracks have thicknesses e $1=1 \mathrm{~mm}$, e $2=4 \mathrm{~mm}$, and e $3=8 \mathrm{~mm}$, and they are placed in the slab at different depths "p", with $\mathrm{p}=[1 \mathrm{~cm}, 3 \mathrm{~cm}, 6 \mathrm{~cm}$, and $9 \mathrm{~cm}]$.

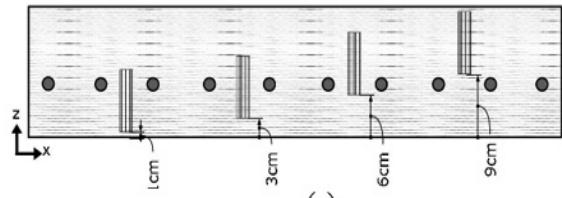

(a)



(b)

Fig. 28. Cross-section according to (xoz) (a) and according to (yoz) (b).

\section{Effect of crack depth}

The thermogram in Fig. 29(a) represents the distribution of the temperature in the bottom surface; Fig. 29(b) and Fig. 30, respectively, represent the evolution of the temperature profiles along the lines A1A2, A3A4, and A5A6. 


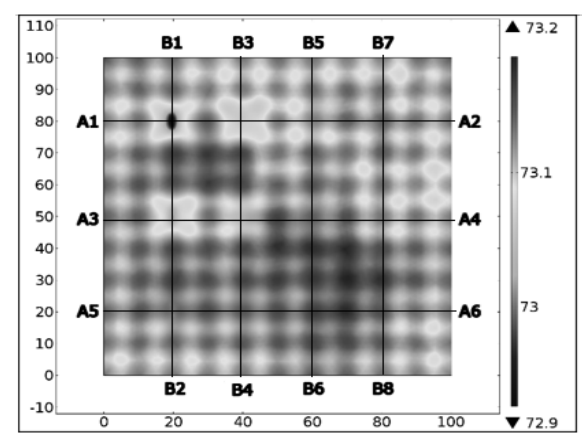

(a)

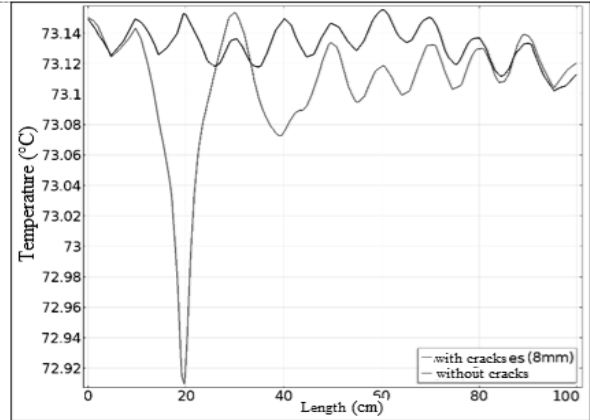

(b)

Fig. 29. Thermal image (a) and temperature evolution along A1A2 (b).

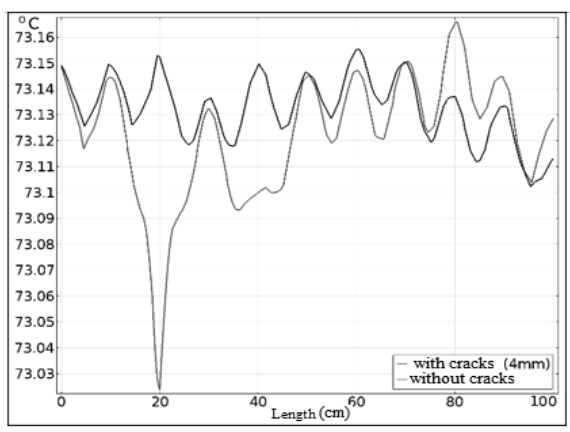

(a)

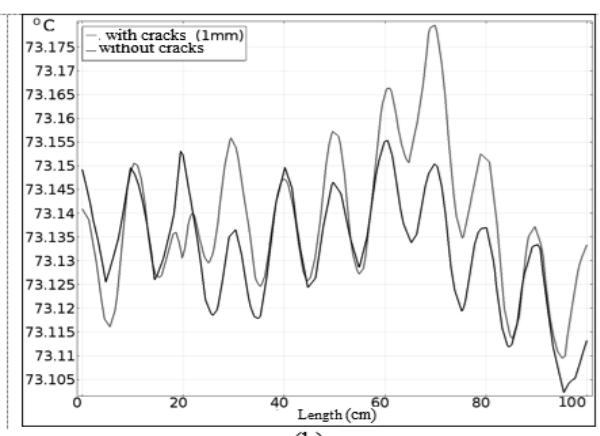

(b)

Fig. 30. Evolution along axes A3A4 (a) and A5A6 (b).

From the previous figures it is noted that the detection of vertical cracks is difficult compared to the previous horizontal cracks. The observed defect contrast becomes less clear as the depth increases. In addition, only defects located at the intersection of the lines $\{(\mathrm{A} 1 \mathrm{~A} 2),(\mathrm{B} 1 \mathrm{~B} 2)\},\{(\mathrm{A} 3 \mathrm{~A} 4),(\mathrm{B} 1 \mathrm{~B} 2)\},\{(\mathrm{A} 1 \mathrm{~A} 2),(\mathrm{B} 3 \mathrm{~B} 4)\}$, and $\{(\mathrm{A} 3 \mathrm{~A} 4)$, (B3B4)\} are detectable.

\section{Effect of crack thickness}

The curve in Fig. 31 represents the evolution of the temperature profile of the lower heated surface, along the lines B1B2 and B3B4. It can be seen that the temperature passes through a minimum in the case of a thickness defect e $3=8$ $\mathrm{mm}$, which is closer to the low surface, and the detectability of the defect increases with the value of thickness e.



Fig. 31. Evolution of temperatures along the lines B1B2 and B3B4. 
The defects represent, on one side, a temperature difference of $0.20^{\circ} \mathrm{C}(\mathrm{e} 3=8 \mathrm{~mm})$ and $0.13{ }^{\circ} \mathrm{C}(\mathrm{e} 2=4 \mathrm{~mm})$ on the $\mathrm{B} 1 \mathrm{~B} 2$ line; in this case, the detection of the presence of defect will be simple, with an equipment of the first category of sensitivity lower than $0.06^{\circ} \mathrm{C}$. On the other hand, with differences of $0.08{ }^{\circ} \mathrm{C}(\mathrm{e} 3=8 \mathrm{~mm})$ and $0.04^{\circ} \mathrm{C}(\mathrm{e} 2=4 \mathrm{~mm})$ on the line B3B4, in this case, it is necessary to have a very sensitive apparatus of the third category of sensitivity lower than $0.035^{\circ} \mathrm{C}$.

\section{Diameter effect of steel bars}

In this simulation, we use the same vertical crack placed in a slab at a depth $p=1 \mathrm{~cm}$. The adopted structure is shown in Fig. 32. The steel bars have, respectively, $d=10 \mathrm{~mm}, 20 \mathrm{~mm}$, and $32 \mathrm{~mm}$ diameter.



Fig. 32. Cross-section according to the plan (yoz).

Fig. 33 shows the simulated thermographic image on the lower surface of the slab, and Fig. 34 shows the temperature difference along the line $\mathrm{AB}$.

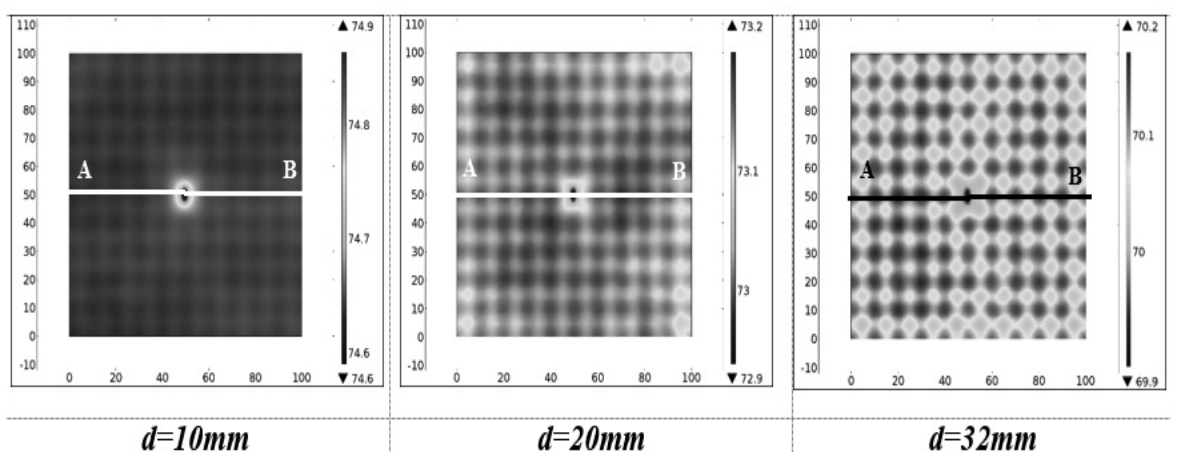

Fig. 33. Thermograms for different diameters of steel.

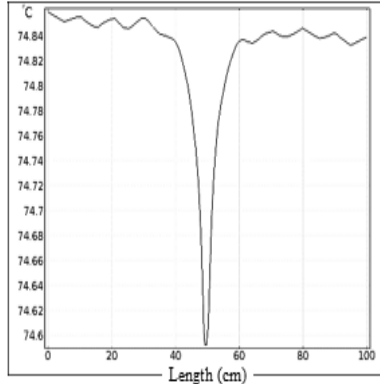

$d=10 \mathrm{~mm}$
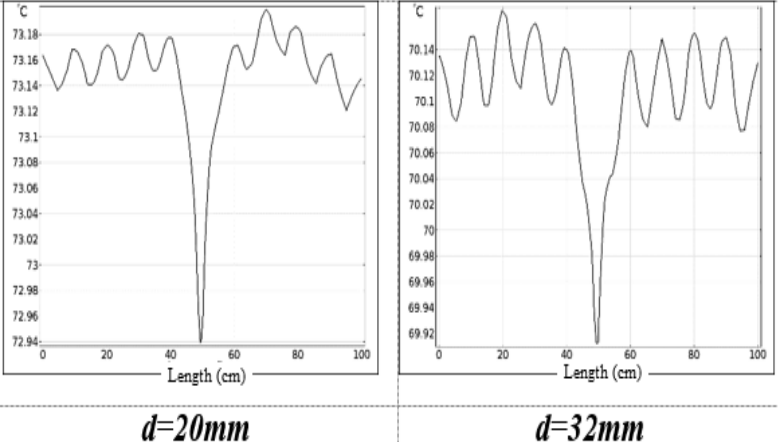

Fig. 34. Temperature evolution along the $\mathrm{AB}$ axis for different diameters. 
The results shown in Figs. 33 and 34 show that the greater the diameter of the steel bars, the greater the thermal resistance of the bars, and consequently the thermal conductivity decreases, making the detectability more difficult.



Fig. 35. Histogram of the different temperature $\Delta \mathrm{T}$ according to the diameter of the steel bars.

Fig. 35 shows that the detection of the presence of defects in this case would be simple, with appropriate equipment.

\section{Effect of thermophysical parameters}

In order to illustrate the influence of the thermophysical parameters on the detection of the vertical crack, we considered the slab structure (Fig. 36.a), which contains three defects (vertical cracks), located at a depth $\mathrm{p}=1 \mathrm{~cm}$ (Fig. 37.b).

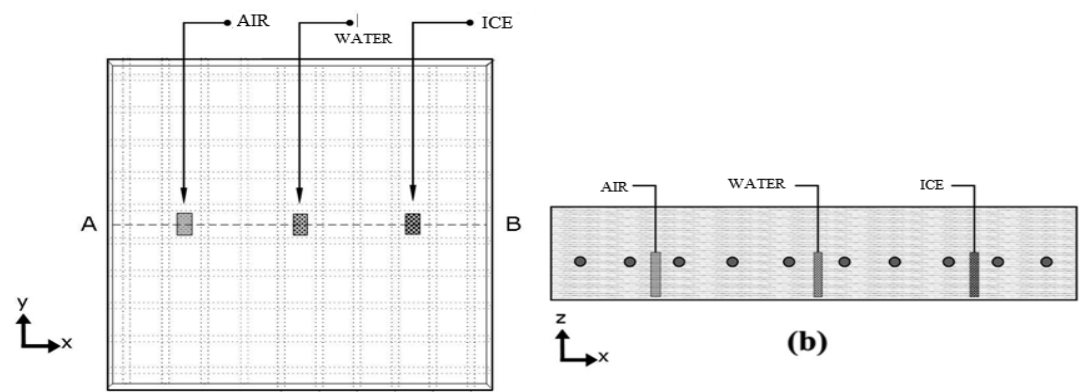

(a)

Fig. 36. Description of the structure: (a) upper surface, (b) sectional view (xoz) of the slab.

Fig. 37(a) represents the simulated thermographic image of the lower surface of the slab with existence of three vertical cracks of different nature, and Fig. 37(b) represents the temperature profile along the $\mathrm{AB}$ axis.
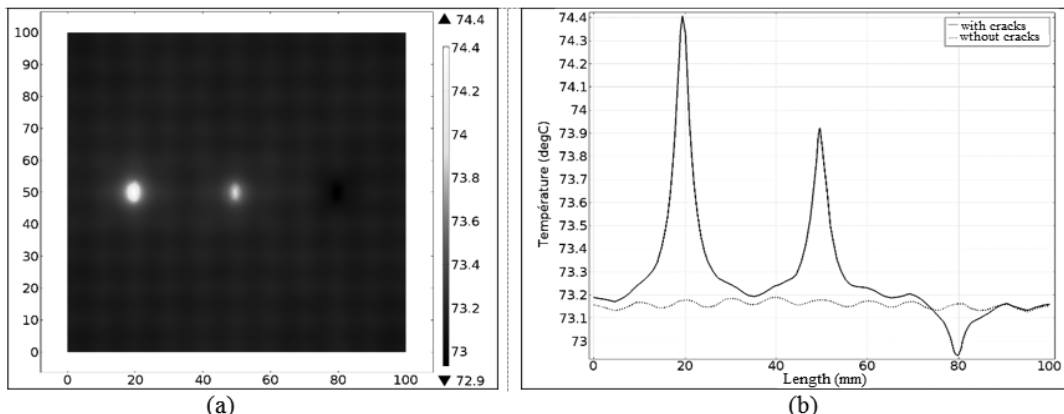

(b)

Fig. 37. Temperature thermogram (a) and temperature distribution along the $\mathrm{AB}$ axis (b). 
From these results it can be noted that the shape of these temperature profiles is different from one defect to another. As in the case of a horizontal crack, the nature of the defect (air, water, and ice) acts differently on the heat flow through the concrete structure. Air and water type anomalies accumulate heat, which generates an increase in the temperature compared to the neighborhood. In addition, the ice-type anomaly absorbs the heat flow, which causes a drop in the temperature in this area compared to its neighborhood.

\section{Temporal study}

The use of infrared cameras can be so attractive and so popular in the inspection of works in general and slabs in particular. However, several factors can make their use very difficult, especially, the length of time needed to detect defects. In this part, we are interested in the temporal study of a vertical defect located in a reinforced concrete slab. With an infrared camera, we have an immediate overview of our entire system, and thanks to the heat emitted by the latter, the study of vertical cracks that we made allowed us to mount that only 4 cracks are detectable. In the following, we will define the duration of heating of the structure necessary to recognize each defect. For this, we adapted the same model used previously, leaving only detectable defects in the permanent domain (Fig. 38).

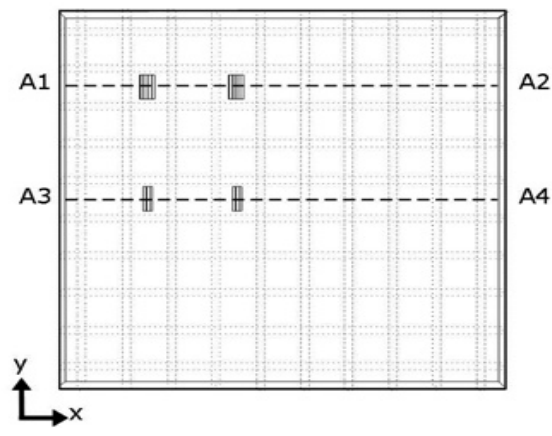

Fig. 38. View of the upper side.

Constant heat flux $\left(\mathrm{Q}=500 \mathrm{~W} / \mathrm{m}^{2}\right)$ is applied to the lower surface of the slab for a certain determined period of time in order to cause a temperature difference $\Delta \mathrm{T}$ sufficiently measurable by the camera between the normal zones of the slab and the defective areas. Several thermal images have been taken, and those given above are images at the moment when the defects start to become detectable by the infrared camera. Fig. 39 shows the recorded thermograms of the lower surface, and Figs. 40 and 41 show the evolution of the temperature profile along the lines A1A2 and A3A4 after a heating period $\mathrm{t} 1=10 \mathrm{~min}, \mathrm{t} 2=1 \mathrm{~h}$, and $\mathrm{t} 3=2.5 \mathrm{~h}$.
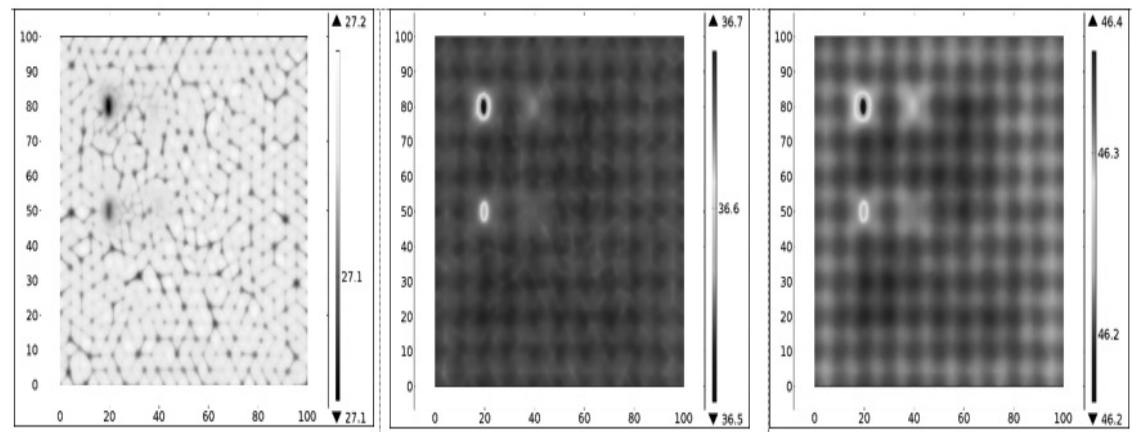

Fig. 39. Thermograms for durations (a) $t 1=10 \mathrm{~min}$; (b) $\mathrm{t} 2=1 \mathrm{~h}$; (c) $\mathrm{t} 3=2.5 \mathrm{~h}$. 




(a)

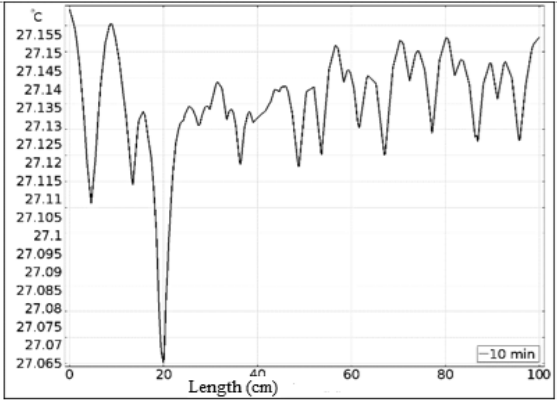

(b)

Fig. 40. Temperature evolution on $\mathrm{A} 1 \mathrm{~A} 2$ (a) at $\mathrm{t}=10 \mathrm{~min}$ and on $\mathrm{A} 3 \mathrm{~A} 4$ at $\mathrm{t}=10 \mathrm{~min}$ (b).

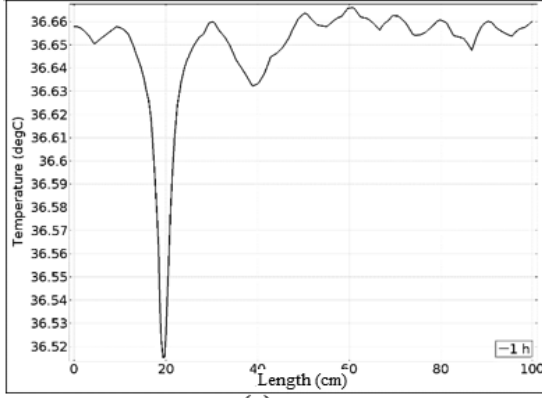

(a)



(b)

Fig. 41. Temperature evolution on $\mathrm{A} 1 \mathrm{~A} 2$ (a) at $\mathrm{t}=1 \mathrm{~h}$ and on $\mathrm{A} 3 \mathrm{~A} 4$ at $\mathrm{t}=2.25 \mathrm{~h}(\mathrm{~b})$.

In the graph of Fig. 40(a), after 10 minutes of heating, the temperature difference between the structure and the defect at the position $\mathrm{x}=20 \mathrm{~cm}$ resulted in (position of the thickness defect $\mathrm{e} 3=8 \mathrm{~mm}$ ) $\mathrm{Ta}-\mathrm{Tb}=0.08{ }^{\circ} \mathrm{C}$. In the following graph of Fig. 40(b), for heating the same duration, the resulting temperature difference at the position $\mathrm{x}=20$ $\mathrm{cm}$ along the line $\mathrm{A} 3 \mathrm{~A} 4$ was $\mathrm{Ta}-\mathrm{Tb}=0.07{ }^{\circ} \mathrm{C}$. These two figures show, on one side, that the heating of a period of 10 minutes is not sufficient to detect defects that are at a depth $\mathrm{p}=3 \mathrm{~cm}$. And, on the other hand, cracks located at $\mathrm{p}=1 \mathrm{~cm}$ are easily detectable. The thermal profile along the line A1 A2 (Fig. 41(a)) shows that, at time $\mathrm{t} 2=1 \mathrm{~h}, \Delta \mathrm{T} 1=0.14^{\circ} \mathrm{C}$ at position $\mathrm{x}=20 \mathrm{~cm}$ and $\Delta \mathrm{T} 2=0.035^{\circ} \mathrm{C}$ at position $\mathrm{x}=40 \mathrm{~cm}$. The thermal profile along line A3A4 (Fig. $41(\mathrm{~b})$ ) shows that, at time $\mathrm{t} 3=2.25 \mathrm{~h}, \Delta \mathrm{T} 1=0.09{ }^{\circ} \mathrm{C}$ at the position $\mathrm{x}=20 \mathrm{~cm}$ and $\Delta \mathrm{T} 2=0.02{ }^{\circ} \mathrm{C}$ at the position $\mathrm{x}=40 \mathrm{~cm}$. It can be seen that there is a tendency toward detectability of defects as one approaches the bottom surface and is heated.

\section{CONCLUSION}

As a conclusion, we realized the effect of several parameters on the detectability of cracks in a reinforced concrete slab, especially, horizontal and vertical anomalies. In order to know the impact of the depth, the effect of the thickness, the effect of diameter of the steel bars, and nature of the material of the crack are analyzed. The results of the different simulations carried out in this study show

- $\quad$ the ability to detect horizontal cracks by interpreting the distribution of temperature on the lower surface of the slab, and it is sufficient to have a nondestructive testing equipment of high thermal sensitivity $\left(<0.035{ }^{\circ} \mathrm{C}\right)$;

- cracks that can be easily detected and analyzed in cases where they are near the bottom face, when they have relatively large thicknesses or when they are located in a slab with a small diameter reinforcement network;

- that we have also shown that the detectability of cracks in the transient regime is possible as in the case of the steady state, provided to apply a sufficient heat flux and to have a significant difference between the conductivity of the material and that of the defect, as well as being located at depths near the underside of the slab. 
With regard to vertical cracks,

- we carried out a permanent study of the evolution of the temperature according to the geometric and thermophysical characteristics of the defect. This allowed us to conclude that only defects that have a thickness greater than or equal to $4 \mathrm{~mm}$, which are at a depth less than or equal to $3 \mathrm{~cm}$, are detectable by means of an appropriate apparatus. Time plays a determining role in the thermal response of the material and in the feasibility of measurements. By studying the influence of this parameter on detectability, we showed that the detectable defects in steady state can be detected quickly. In the transient regime, the defects which are at a depth $\mathrm{p}=1 \mathrm{~cm}$ enter the detectability zone after a heating period, which does not exceed 10 minutes. However, when the depth $\mathrm{p}=3 \mathrm{~cm}$, the defects will not be detectable after one hour for a thickness defect $\mathrm{e}=8 \mathrm{~mm}$, and after 2 hours and 15 minutes for a thickness defect $\mathrm{e}=8 \mathrm{~mm}$.

\section{REFERENCES}

Arndt, R.W. 2010. Square pulse thermography in frequency domain as adaptation of pulsed phase thermography for qualitative and quantitative applications in cultural heritage and civil engineering. Infrared Phys. Technol. 53: 246-253.

Balayssac, J.P., Laurens, S., Arliguie, G., Breysse, D., Garnier, V. \& Derobert, X. 2012. Description of the general outlines of the French project SENSO - quality assessment and limits of different NDT methods. Constr. Build. Mater. 35: 131-138.

Bomberg, M. \& Shirtliffe, C. 1988. Influence of moisture and moisture gradients on heat transfer through porous building materials. ASTM STP 660: 211-233.

Cotič P., Kolarič, D., Bosiljkov, V.B., Bosiljkov, V. \& Jagličić, Z. 2015. Determination of the applicability and limits of void and delamination detection in concrete structures using infrared thermography. NDT \& E International 74: 87-93.

Fox, M., Coley, D., Goodhew, S. \& Wilde, P. 2014. Thermography methodologies for detecting energy related building defects. Ren. Sus. Ener. Rev. 40: 296-310.

Hart, J.M. 1990. An introduction to infra-red thermography for building surveys. BRE Information paper.

Ibarra, C.C., Galmiche, F., Darabi, A., Pilla, M., Klein, M., Ziadi, A., Vallerand, S., Pelletier, J.F. \& Maldague, X.P. 2003. Thermographic nondestructive evaluation: Overview of recent progress. Proceeding of Thermosense XXV. Orlando, Florida.

IAEA, 2002. Guidebook on non-destructive testing of concrete structures, IAEA-TCS-17, Vienna: 129-136.

Janku, M., Brezina, I. \& Grosek, J. 2017. Use of infrared thermography to detect defects on concrete bridges. Pocedia Engineering 190: $62-69$.

Jianda, X.,Guoxin, Z., Yi, L., Zhenhong, W. \& Zhe, W. 2020. Numerical analysis of effect of temperature history and restraint degree on cracking behavior of early-age concrete. Journal of Engg. Research 8 (2): 24-43.

Kaylili, A., Fokaides, P.A., Christou, P. \& Kalogirou, S.A. 2014. Infrared thermography (IRT) applications for building diagnostics: A review. Applied Energy 134: 531-549.

Laure, L. 2006. Concrete cracking analysis and implementation techniques in order to optimize the realization of the works. Report, INSA, Strasbourg, France.

Ljungberg, S.A. 1994. Infrared Techniques in Buildings and Structures: Operation and maintenance. Pp. 211-241. Gavle, Sweden.

Meola, C. \& Carlomagno, G.M. 2006. Application of infrared thermography to adhesion science. J. Adhes. Sci. Technol. 20: 589-632.

Noufid, A. \& Belattar, S. 2019. Infrared thermography and finite element method applied to the detection of internal defects in reinforced concrete slabs. Journal of Engg. Research 8 (2): 125-142.

Poblete, A. \& Pascual, M.A. 2007. Thermographic measurement of the effect of humidity in mortar porosity. Infrared Phys. Technol. 49: 224-227.

Sivakumar, A., Saiful, I. \& Roohul, A. 2019. Effect of steel fibre profile on the fracture characteristics of steel fibre reinforced concrete beams. Journal of Engg. Research 7 (2): 105-124.

Usamentiaga, R., Venegas, P., Guerediaga, J., Vega, L., Molleda, J. \& Bulnes, G.F. 2014. Infrared Thermography for Temperature Measurement and Non-Destructive Testing. Sensors 14: 12305-12348. 